\title{
NMR Theoretical Studies of Trapped Cations inside Fullerenes
}

\author{
Fatemeh Mollaamin* \\ Department of French Language and Literature, Iran \\ *Corresponding author: Fatemeh Mollaamin, Department of French Language and Literature, Tehran, Iran
}

Submission: 眥 August 27, 2018; Published: 眥 October 24, 2018

\begin{abstract}
To probe the ability of Cations to enter, we have calculated the charge and $\mathrm{NMR}$ parameters of a direct diffusion pathway for $\mathrm{H}^{+}$, $\mathrm{Li}^{+}$, $\mathrm{Na}^{+}$, $\mathrm{K}^{+}$Cations to move through the $\mathrm{C}_{60}, \mathrm{C}_{70}$ and $\mathrm{C}_{80}$ fullerenes with density functional theory (DFT) technique. These Cations could easily diffuse along the central axis of $\mathrm{C}_{60}, \mathrm{C}_{70}$ and $\mathrm{C}_{80}$ fullerenes with distance of 4.9,3.678,2.433,1.249 and in the center of cage system. In this work, the charge and NMR calculations with B3LYP/6-31+G**/6-31++G** levels have indicated that the Cationic fullerene cages are very stable molecules and do not have the reactivity associated with ordinary empty fullerenes.

A common feature of these curves has characterized by three local minima which has located near the $\mathrm{H}^{+}, \mathrm{Li}^{+}, \mathrm{Na}^{+}, \mathrm{K}^{+}$that hydrogen, lithium and sodium Cations had a good agreement and potassium Cation had a little deviation in $\mathrm{NMR}$ parameters. Also, In all $\mathrm{FH}^{+}, \mathrm{FLi}^{+}, \mathrm{FNa}^{+}$, and $\mathrm{FK}^{+}$systems, the charge has transferred between ion and fullerene and then fullerene has been achieved the positive charge. These compounds can be miniaturized electronics beyond the micro electromechanical scale currently used in electronics.
\end{abstract}

Keywords: Fullerene; $\mathrm{C}_{60}, \mathrm{C}_{70}$ and $\mathrm{C}_{80} ; \mathrm{H}^{+}, \mathrm{Li}^{+}, \mathrm{Na}^{+}, \mathrm{K}^{+}$Cations charge; DFT; NMR

\section{Introduction}

A fullerene is any molecule composed entirely of carbon, in the form of a hollow sphere, ellipsoid, or tube. Spherical fullerenes are also called buckyballs and they resemble the balls used in association football. Cylindrical ones are called carbon nanotubes or buckytubes. Fullerenes are similar in structure to graphite, which is composed of stacked graphene sheets of linked hexagonal rings; but they may also contain pentagonal (or sometimes heptagonal) rings [1].

The first fullerene to be discovered, and the family's namesake, buckminsterfullerene $\left(\mathrm{C}_{60}\right)$, was prepared in 1985 by Richard Smalley, Robert Curl, James Heath, Sean O'Brien, and Harold Kroto at Rice University. The name was homage to Buckminster Fuller, whose geodesic domes it resembles. The structure was also identified some five years earlier by Sumio Iijima, from an electron microscope image, where it formed the core of a "bucky onion" [2]. Fullerenes have since been found to occur in nature [2]. More recently, fullerenes have been detected in outer space [3]. According to astronomer Letizia Stanghellini, "It's possible that buckyballs from outer space provided seeds for life on Earth" [3].

Fullerenes are stable, but not totally unreactive. The $\mathrm{sp}^{2}$ hybridized carbon atoms, which are at their energy minimum in planar graphite, must be bent to form the closed sphere or tube, which produces angle strain. The characteristic reaction of fullerenes is electrophilic addition at 6,6-double bonds, which reduces angle strain by changing $\mathrm{sp}^{2}$-hybridized carbons into $\mathrm{sp}^{3}$ hybridized ones. The change in hybridized orbitals causes the bond angles to decrease from about $120^{\circ}$ in the $\mathrm{sp}^{2}$ orbitals to about $109.5^{\circ}$ in the $\mathrm{sp}^{3}$ orbitals. This decrease in bond angles allows for the bonds to bend less when closing the sphere or tube, and thus, the molecule becomes more stable.

Other atoms can be trapped inside fullerenes to form inclusion compounds known as endohedral fullerenes [4]. Recent evidence for a meteor impact at the end of the Permian period was found by analyzing noble gases so preserved [5]. Metallofullerene-based inoculates using the rhonditic steel process are beginning production as one of the first commercially-viable uses of buckyballs. Fullerene purification remains a challenge to chemists and to a large extent determines fullerene prices. So-called endohedral fullerenes have ions or small molecules incorporated inside the cage atoms. Fullerene is an unusual reactant in many organic reactions such as the Bingel reaction discovered in 1993. Carbon nanotubes were recognized in 1991[6].

Minute quantities of the fullerenes, in the form of $\mathrm{C}_{60}, \mathrm{C}_{70}, \mathrm{C}_{76}$, and $\mathrm{C}_{84}$ molecules, are produced in nature, hidden in soot and formed by lightning discharges in the atmosphere. In 1992, fullerenes were found in a family of minerals known as Shungites in Karelia, Russia. In 2010 , fullerenes $\left(C_{60}\right)$ have been discovered in a cloud of cosmic dust surrounding a distant star 6500 light years away [7]. Another 
common fullerene is $\mathrm{C}_{70}$ [7], but fullerenes with $72,76,84$ and even up to 100 carbon atoms are commonly obtained.

This class of novel molecules comprises 80 carbon atoms $\left(\mathrm{C}_{80}\right)$ forming a sphere which encloses a complex of three metal atoms and one nitrogen atom [8]. Transport of molecules through molecular pores is essential for many biological and technical processes [9]. Pores in zeolites [10] and biological channels [11-13] are often too narrow for ions or small molecules to pass each other, but wide enough to be conducted in a single-file arrangement. Molecular transport through the sequasi-one-dimensional pores is highly collective, since motion of a molecule requires concomitant motion of all molecules in the file $[9,14]$.

Some early attempts to design channels for transport of ions and molecules involved the preparation of cylindrical structures or compounds that looked cylindrical $[12,15]$. Carbon nanostructure, a new form of element carbon, is composed of grapheme sheets rolled into closed concentric cylinders with diameter of the order of nanometers and length of micrometers. Since its discovery by Iijima [16], extensive applications have been found in physical, chemical, biological and material science fields. Also, Singlewalled nanotubes are the most likely candidate for miniaturizing electronics beyond the micro electromechanical scale currently used in electronics [17].

The most basic building block of these systems is the electric wire, and SWNTs can be excellent conductors $[18,19]$. One useful application of SWNTs is in the development of the first intramolecular field effect transistors (FET). Production of the first intramolecular logic gate using SWNT FETs has recently become possible as well [20]. To create a logic gate, you must have both a p-FET and an n-FET. Because SWNTs are p-FETs when exposed to oxygen and n-FETs otherwise, it is possible to protect half of an SWNT from oxygen exposure, while exposing the other half to oxygen. This results in a single SWNT that acts as a NOT logic gate with both $\mathrm{p}$ and $\mathrm{n}$-type FETs within the same molecule.

$\mathrm{Ab}$ initio investigations of Lithium diffusion in carbon nanotube systems [21,22], the potential energy curves for $\mathrm{H}_{2}$ penetration into the open-ended nanotube [23,24] and molecular dynamics (MD) simulation of water inside single-walled carbon nanotubes $[17,25-28]$ have been reported. In this study, to probe the ability of along the central axis of $\mathrm{C}_{60}, \mathrm{C}_{70}$ and $\mathrm{C}_{80}$ fullerenes with distance of $4.9,3.678,2.433,1.249$ and in the center of cage, we have calculated the NMR parameters of a diffusion pathway for each of ions to move through the inside of $\mathrm{C}_{60}, \mathrm{C}_{70}$ and $\mathrm{C}_{80}$ fullerenes.

Since the $\mathrm{H}^{+}, \mathrm{Li}^{+}$and $\mathrm{Na}^{+}$ions used in this study generally transfer electron density to a localized region on the fullerenes $[22,29,30]$, we have investigated the change of partial charges distribution in effect of transport of Cations, too. All calculations in this work were performed with $6-31+G^{* *}$ and $6-31++G^{* *}$ basis set of B3LYP level of the Gaussian03W suite of software [31]

\section{Computational Method}

There are many calculations that have been done using abinitio quantum methods applied to fullerenes. By DFT and TD-DFT methods one can obtain IR, Raman and UV spectra. Results of such calculations can be compared with experimental results.

In order to investigate the movement of ions through Fullerenes, we calculated the potential energy of a diffusion pathway for $\mathrm{H}^{+}, \mathrm{Li}^{+}$, $\mathrm{Na}^{+}$and $\mathrm{K}^{+}$Cations along the central axis of $\mathrm{C}_{60}, \mathrm{C}_{70}$ and $\mathrm{C}_{80}$ fullerenes with distance of 4.9,3.678,2.433,1.249 and in the center of cage, as shown in Figure 1. Because of the large size of fullerenes $\left(\mathrm{C}_{60}, \mathrm{C}_{70}\right.$ and $\mathrm{C}_{80}$, respectively), high level calculations of the full system were impractical. For this, we adopt the $6-31+G^{* *}$ and $6-31++G^{* *}$ basis sets of B3LYP method of the Gaussian 03 program package [31].

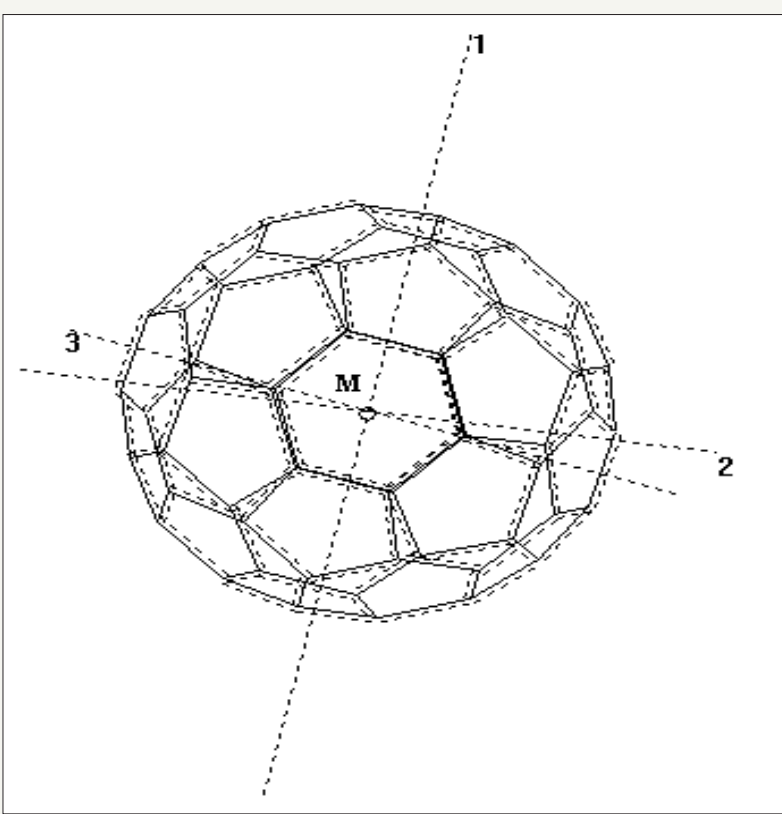

Figure 1: Configuration of Cation penetration $\left(\mathrm{M}=\mathrm{H}^{+}, \mathrm{Li}^{+}, \mathrm{Na}^{+}, \mathrm{K}^{+}\right)$into the optimized $\mathrm{C}_{60}, \mathrm{C}_{70}, \mathrm{C}_{80}$ fullerenes. 
For beginning, the structure of free $\mathrm{C}_{60}, \mathrm{C}_{70}$ and $\mathrm{C}_{80}$ fullerenes were full optimized, then all carbon atoms coordinates were kept frozen and a single ion was moved with about $0.6 \AA$ Asteps along the central axis of the tube from $-10^{\circ} \mathrm{A}$ to $10^{\circ} \mathrm{A}$ respect to the fullerene center of mass and NMR parameters and charges were calculated with the super molecular approach on using the hybrid exchangefunctional B3LYP/6-31+G** $/ 6-31++G^{* *}$ levels of theory [32].

Figure 2 shows curves of potential energy as a function of distance between the center of mass of the nanotube and ion (R/Å) for each of Cations in all hollow spheres. Carbon nanostructures reveal diverse electrical properties depending on the diameter, length and chirality [33]. Besides, in the nanostructure-ion systems, the charge can transfer between ion and nanostructure. For example, using the fullerene $\mathrm{C}_{60}$ model, Pavanello et al. [34] determined that a charge transfer between lithium and external surface of $\mathrm{C}_{60}$ is possible.
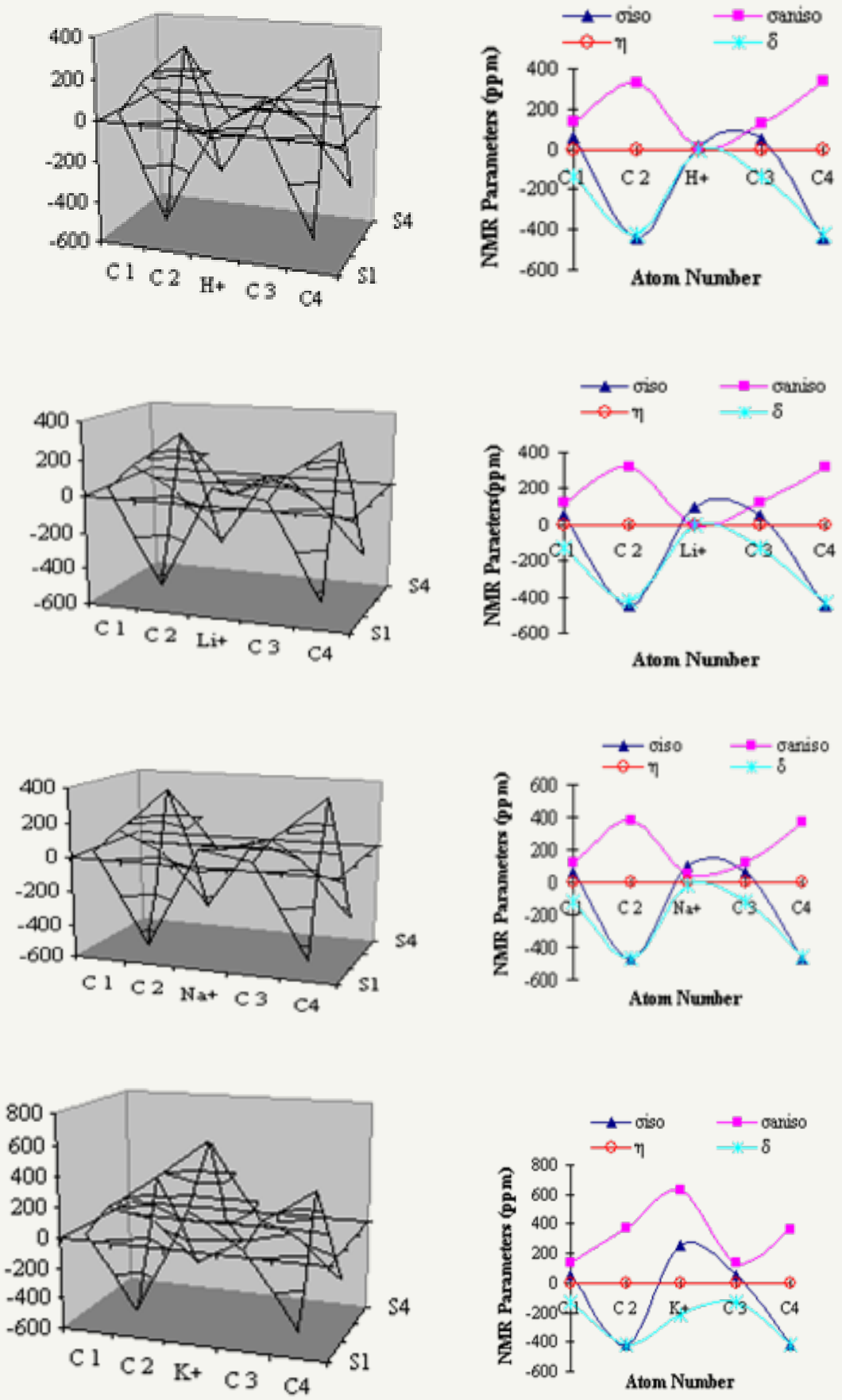

Figure 2: The calculated NMR parameters for $\mathrm{H}^{+}, \mathrm{Li}^{+}, \mathrm{Na}^{+}$and $\mathrm{K}^{+}$Cations entering into various fullerenes $\left(\mathrm{C}_{60}, \mathrm{C}_{70}\right.$ and $\left.\mathrm{C}_{80}\right)$ are given in $\mathrm{B} 3 \mathrm{LYP} / 6-31+\mathrm{G}^{* *}, 6-31++\mathrm{G}^{* *}$ (two basis sets had the same results). 
The availability of methods with small scaling law such as DFT allows reasonable accuracy for sufficiently large model system. For examples, Zhao et al. [35] has performed SCF pseudo potential plane-wave calculation based on local density approximation (LDA) on a periodic Li5C40 system that represents Li-intercalated CNT ropes. Yang and co-workers employed LDA calculations using an electron core potential to study $\mathrm{Li}_{2} \mathrm{C}_{120}, \mathrm{Li}_{2} \mathrm{C}_{132}$ and $\mathrm{Li}_{2} \mathrm{C}_{120} \mathrm{H}_{12}$ that model the Li intercalation in open, closed and $\mathrm{H}$-saturated CNTs, respectively [36].

Therefore, structures of fullerene with various metallic Cations could fully relax during the several optimization processes. Electrical resistance Properties of the structures are calculated using prior calculation. But in NMR scrutiny used prior method with 6-31g**, $6-31+\mathrm{G}^{* *}$ and $6-31++\mathrm{G}^{* *}$ basis sets that two basis sets $6-31+\mathrm{G}^{* *}$, $6-31++G^{* *}$ is had good agreement together in all cases. Hence, we extracted the partial charges and NMR parameters of atoms in $\mathrm{C}_{60}$, $\mathrm{C}_{70}$ and $\mathrm{C}_{80}$ models and hollow sphere-Cation systems.

\section{Results and Discussion}

The discovery of fullerenes greatly expanded the number of known carbon allotropes, which until recently were limited to graphite, diamond, and amorphous carbon such as soot and charcoal. Buckyballs and buckytubes have been the subject of intense research, both for their unique chemistry and for their technological applications, especially in materials science, electronics, and nanotechnology. We have described the interaction potentials of Cations penetration into the indicated fullerenes. To interpret the diameter dependent penetration, we have presented the three kind $\mathrm{C}_{60}, \mathrm{C}_{70}$ and $\mathrm{C}_{80}$ fullerenes (Figure 1).

The aim of this section was to first discuss the different aspects of the electronic structure of the $\mathrm{H}^{+}, \mathrm{Li}^{+}, \mathrm{Na}^{+}$and $\mathrm{K}^{+}$Cations along the central axis of $\mathrm{C}_{60}, \mathrm{C}_{70}$ and $\mathrm{C}_{80}$ fullerenes with distance of $4.9,3.678,2.433,1.249$ and in the center of cage system for further validation of theoretical results to increase their usefulness in practical applications or for pre-experimental modeling with charge measurement of charges of interaction between Cations and carbons in hollow spheres of $\mathrm{C}_{60}, \mathrm{C}_{70}$ and $\mathrm{C}_{80}$ fullerenes (Figure 1) . Second, we have explored the electromagnetic nature of these systems by calculating the following parameters, which provide valuable information on the interaction characteristics (Table 1).

Table 1: Shows the charge of Cations and total charge of hollow sphere $\left(\mathrm{C}_{60}, \mathrm{C}_{70}\right.$ and $\left.\mathrm{C}_{80}\right)$-Cation systems at situations of Cations along central axis of cages.

\begin{tabular}{|c|c|c|c|c|c|c|c|c|}
\hline Fullerene & \multicolumn{8}{|c|}{$\mathrm{C}_{60}$} \\
\hline $\begin{array}{c}\text { NMR Parame- } \\
\text { ters }\end{array}$ & \multicolumn{2}{|c|}{$\sigma_{\text {iso }}$} & \multicolumn{2}{|c|}{$\sigma_{\text {aniso }}$} & \multicolumn{2}{|c|}{$\eta$} & \multicolumn{2}{|c|}{$\delta$} \\
\hline $\begin{array}{c}\text { Level } \\
\text { Atom Number }\end{array}$ & $\begin{array}{c}\text { B3LY- } \\
\text { P/6-31+G** }\end{array}$ & $\begin{array}{c}\text { B3LY- } \\
\text { P/6-31++G** }\end{array}$ & $\begin{array}{c}\text { B3LY- } \\
\text { P/6-31+G** }\end{array}$ & $\begin{array}{c}\text { B3LY- } \\
\text { P/6-31++G** }\end{array}$ & $\begin{array}{c}\text { B3LY- } \\
\text { P/6-31+G** }\end{array}$ & $\begin{array}{c}\text { B3LY- } \\
\text { P/6-31++G** }\end{array}$ & $\begin{array}{c}\text { B3LY- } \\
\text { P/6-31+G** }\end{array}$ & $\begin{array}{c}\text { B3LY- } \\
\text { P/6-31++G** }\end{array}$ \\
\hline & \multicolumn{8}{|c|}{$C_{60}$} \\
\hline C1 & 62.8359 & 62.8826 & 134.3619 & 134.3619 & 0.2288 & 0.2286 & -145.874 & -145.813 \\
\hline C2 & -464.866 & -464.794 & 403.8347 & 403.8347 & 0.0924 & 0.0923 & -492.824 & -492.926 \\
\hline $\mathbf{L i}$ & 99.7341 & 99.731 & 1.2496 & 1.2496 & 0.0099 & 0.0103 & -1.6608 & -1.6491 \\
\hline C3 & 62.8228 & 62.8517 & 134.3729 & 134.3729 & 0.2287 & 0.2285 & -145.862 & -145.832 \\
\hline \multirow[t]{2}{*}{ C4 } & -464.921 & -464.879 & 403.882 & 403.882 & 0.0928 & 0.0925 & -492.838 & -492.87 \\
\hline & \multicolumn{8}{|c|}{$\mathrm{C}_{70}$} \\
\hline C1 & 62.8359 & 55.7788 & 134.4451 & 127.4725 & 0.2288 & 0.3184 & -145.874 & -128.91 \\
\hline C2 & -464.866 & -448.603 & 403.7959 & 323.6367 & 0.0924 & 0.0133 & -492.824 & -425.813 \\
\hline $\mathbf{L i}$ & 99.7341 & 97.7596 & 1.258 & 1.9578 & 0.0099 & 1.5172 & -1.6608 & -1.037 \\
\hline C3 & 62.8228 & 55.8034 & 134.4229 & 127.4453 & 0.2287 & 0.3189 & -145.862 & -128.837 \\
\hline \multirow[t]{2}{*}{ C4 } & -464.921 & -448.764 & 403.9616 & 323.4737 & 0.0928 & 0.0124 & -492.838 & -425.974 \\
\hline & \multicolumn{8}{|c|}{$\mathrm{C}_{80}$} \\
\hline C1 & 55.7787 & 55.4479 & 127.4728 & 126.7297 & 0.3184 & 0.3305 & -128.91 & -126.993 \\
\hline C2 & -448.603 & -448.401 & 323.6369 & 323.5058 & 0.0133 & 0.0223 & -425.812 & -422.729 \\
\hline
\end{tabular}




\begin{tabular}{|c|c|c|c|c|c|c|c|c|}
\hline $\mathbf{L i}$ & 97.7596 & 97.5009 & 1.9578 & 2.6572 & 1.5172 & 1.9015 & -1.037 & -1.3787 \\
\hline C3 & 55.8035 & 55.8489 & 127.4449 & 127.9772 & 0.3189 & 0.3446 & -128.837 & -126.903 \\
\hline \multirow[t]{2}{*}{ C4 } & -448.764 & -449.599 & 323.4737 & 323.8406 & 0.0124 & 0.0204 & -425.974 & -423.121 \\
\hline & \multicolumn{8}{|c|}{$\mathrm{C}_{60}$} \\
\hline C1 & 62.969 & 62.969 & 121.2711 & 121.2711 & 0.1587 & 0.1587 & -139.541 & -139.541 \\
\hline $\mathrm{C} 2$ & -494.801 & -494.801 & 494.9432 & 494.9432 & 0.1964 & 0.1964 & -551.588 & -551.588 \\
\hline $\mathrm{Be}$ & 117.5442 & 117.5442 & 38.0898 & 38.0898 & 1.7333 & 1.7333 & -12.7674 & -12.7674 \\
\hline C3 & 62.9327 & 62.9327 & 121.2282 & 121.2282 & 0.1586 & 0.1586 & -139.508 & -139.508 \\
\hline \multirow[t]{2}{*}{ C4 } & -494.973 & -494.973 & 495.3515 & 495.3515 & 0.1973 & 0.1973 & -551.591 & -551.591 \\
\hline & \multicolumn{8}{|c|}{$\mathrm{C}_{70}$} \\
\hline C1 & 119.7267 & 55.4122 & 55.4122 & 119.7271 & 0.297 & 0.297 & -123.078 & -123.078 \\
\hline C2 & -473.201 & 382.6982 & 382.6982 & 382.697 & 0.0873 & 0.0873 & -469.292 & -469.291 \\
\hline Be & 104.73 & 46.5874 & 46.5874 & 46.5886 & 2.7115 & 2.7115 & -16.7362 & -16.7365 \\
\hline C3 & 55.9182 & 120.7124 & 120.7124 & 120.7125 & 0.3144 & 0.3162 & -122.45 & -122.45 \\
\hline \multirow[t]{2}{*}{$\mathrm{C} 4$} & -474.368 & 378.8439 & 378.8439 & 378.8437 & 0.0811 & 0.0811 & -467.206 & -467.206 \\
\hline & \multicolumn{8}{|c|}{$\mathrm{C}_{80}$} \\
\hline C1 & 55.2798 & 55.2796 & 119.7095 & 119.7094 & 0.3154 & 0.3154 & -121.341 & -121.341 \\
\hline C2 & -472.666 & -472.666 & 377.2317 & 377.2328 & 0.0811 & 0.1038 & -465.221 & -465.221 \\
\hline $\mathrm{Be}$ & 103.8243 & 103.8242 & 47.3187 & 47.3175 & 2.6822 & 2.6822 & -17.1338 & -17.1334 \\
\hline C3 & 55.8703 & 55.8696 & 120.8302 & 120.8301 & 0.3348 & 0.3348 & -120.692 & -120.693 \\
\hline \multirow[t]{2}{*}{ C4 } & -473.925 & -473.925 & 372.3987 & 372.3987 & 0.073 & 0.073 & -462.709 & -462.709 \\
\hline & \multicolumn{8}{|c|}{$\mathrm{C}_{60}$} \\
\hline C1 & 61.1762 & 56.4495 & 142.1951 & 145.4579 & 0.2616 & 0.2506 & -150.278 & -155.072 \\
\hline C2 & -456.963 & -470.549 & 422.6444 & 406.342 & 0.1494 & 0.1251 & -490.257 & -481.529 \\
\hline $\mathrm{Na}$ & 11.799 & 11.4407 & 4.4827 & 4.6796 & 0.0002 & 0.0095 & -5.9756 & -6.1803 \\
\hline C3 & 61.1518 & 55.7247 & 142.187 & 146.1629 & 0.2615 & 0.2485 & -150.281 & -156.085 \\
\hline \multirow[t]{2}{*}{$\mathrm{C} 4$} & -457.026 & -467.415 & 422.8011 & 417.5641 & 0.1498 & 0.1578 & -490.286 & -480.847 \\
\hline & \multicolumn{8}{|c|}{$\mathrm{C}_{70}$} \\
\hline C1 & 54.5721 & 54.5706 & 135.619 & 135.6193 & 0.3656 & 0.3656 & -132.409 & -132.408 \\
\hline $\mathrm{C} 2$ & -443.862 & -443.866 & 332.1998 & 332.2003 & 0.042 & 0.042 & -425.04 & -425.041 \\
\hline $\mathrm{Na}$ & 10.6688 & 10.6688 & 4.7192 & 4.7192 & 0.1988 & 0.1988 & -5.2488 & -5.2489 \\
\hline C3 & 52.7504 & 52.7485 & 132.0534 & 132.0471 & 0.3182 & 0.3182 & -133.56 & -133.559 \\
\hline \multirow[t]{2}{*}{ C4 } & -439.665 & -439.662 & 342.0236 & 342.0336 & 0.0758 & 0.0758 & -423.873 & -423.877 \\
\hline & \multicolumn{8}{|c|}{$\mathrm{C}_{80}$} \\
\hline C1 & 336.7676 & 52.7353 & 52.7942 & 130.1132 & 0.3209 & 0.3264 & -130.556 & -130.788 \\
\hline C2 & 129.342 & -445.445 & -444.433 & 334.1012 & 0.057 & 0.051 & -424.775 & -424.212 \\
\hline $\mathrm{Na}$ & 10.624 & 10.6558 & 4.7034 & 4.5571 & 0.2193 & 0.1796 & -5.1432 & -5.1508 \\
\hline C3 & 52.6318 & 51.835 & 132.9151 & 129.2435 & 0.3417 & 0.3065 & -132.086 & -131.896 \\
\hline \multirow[t]{2}{*}{ C4 } & -438.081 & -436.118 & 338.1488 & 344.6779 & 0.0732 & 0.0886 & -420.102 & -422.16 \\
\hline & \multicolumn{8}{|c|}{$\mathrm{C}_{60}$} \\
\hline C1 & 58.6742 & 52.9451 & 141.6546 & 132.2658 & 0.2542 & 0.3207 & -150.585 & -133.525 \\
\hline C2 & -435.818 & -417.129 & 452.8176 & 369.006 & 0.2587 & 0.3241 & -479.653 & -414.975 \\
\hline $\mathbf{K}$ & 264.8547 & 259.8272 & 615.6712 & 624.0286 & 2.9916 & 2.9552 & -205.652 & -210.365 \\
\hline C3 & 58.6365 & 53.9917 & 141.5431 & 132.8731 & 0.2542 & 0.3437 & -150.473 & -131.842 \\
\hline
\end{tabular}




\begin{tabular}{|c|c|c|c|c|c|c|c|c|}
\hline $\mathrm{C} 4$ & -435.824 & -418.129 & 453.1034 & 366.7424 & 0.2591 & 0.1769 & -479.799 & -415.483 \\
\hline & \multicolumn{8}{|c|}{$\mathrm{C}_{70}$} \\
\hline $\mathrm{C} 1$ & 52.6335 & 52.9451 & 132.1474 & 132.2658 & 0.3171 & 0.3207 & -133.772 & -133.525 \\
\hline $\mathrm{C} 2$ & -417.337 & -417.129 & 369.3955 & 369.006 & 0.1861 & 0.1856 & -415.217 & -414.975 \\
\hline $\mathbf{K}$ & 257.7659 & 259.8272 & 624.6623 & 624.0286 & 2.9626 & 2.9552 & -210.181 & -210.365 \\
\hline $\mathrm{C} 3$ & 53.7841 & 53.9917 & 132.8798 & 132.8731 & 0.3434 & 0.3437 & -131.884 & -131.842 \\
\hline \multirow[t]{2}{*}{$\mathrm{C} 4$} & -418.447 & -418.129 & 366.8031 & 366.7424 & 0.175 & 0.1769 & -418.447 & -415.483 \\
\hline & \multicolumn{8}{|c|}{$\mathrm{C}_{80}$} \\
\hline $\mathrm{C} 1$ & 53.1057 & 53.1057 & 131.6613 & 131.6613 & 0.3337 & 0.3337 & -131.624 & -131.624 \\
\hline $\mathrm{C} 2$ & -417.395 & -417.395 & 365.5737 & 365.5737 & 0.1826 & 0.1826 & -412.138 & -412.138 \\
\hline $\mathbf{K}$ & 260.3325 & 260.3325 & 625.7481 & 625.7481 & 2.9428 & 2.9428 & -211.604 & -211.604 \\
\hline $\mathrm{C} 3$ & 54.0521 & 54.0521 & 132.1971 & 132.1971 & 0.3549 & 0.3549 & -130.089 & -130.089 \\
\hline C4 & -418.26 & -418.26 & 363.4695 & 363.4695 & 0.1744 & 0.1744 & -412.624 & -412.624 \\
\hline
\end{tabular}

A common feature of these curves has characterized by three local minima which has located near the $\mathrm{H}^{+}, \mathrm{Li}^{+}, \mathrm{Na}^{+}$and $\mathrm{K}^{+}$that hydrogen, lithium and sodium Cations had a good agreement and potassium Cation had a little deviation in NMR parameters. The potential barrier between two minima have been decreased in $\mathrm{C}_{2}$ and $\mathrm{C}_{4}$ in all three $\mathrm{C}_{60}, \mathrm{C}_{70}$ and $\mathrm{C}_{80}$ fullerenes (Figure 2). This is because the wave functions of carbon atoms and that of Cations do not overlap significantly for smaller fullerenes, in particular for small ions. These compounds can be miniaturized electronics beyond the micro electromechanical scale currently used in electronics.

In Table, has shown the change of charge distribution associated with moving the ions along the central axis of fullerenes: the charge of Cations and sum of charges distributed over all atoms of hollow spheres of $\mathrm{C}_{60}, \mathrm{C}_{70}$ and $\mathrm{C}_{80}$. In $\mathrm{C}_{60}, \mathrm{C}_{70}$ and $\mathrm{C}_{80}$ the Cations had nonbonded interactions. Note that because of a mirror image charge which forms on the both side of fullerene center, we have shown half of fullerenes.

In all $\mathrm{FH}^{+}$systems, the fullerene had much of positive charge that it increases when the diameter of fullerene increases and reach to +1.922 in the center of the $\mathrm{C}_{80}$ fullerene versus the -0.922 charge of $\mathrm{H}^{+}$Cation. In the case of other Cations: the $\mathrm{Li}^{+}, \mathrm{Na}^{+}$and $\mathrm{K}^{+}$held the most of positive charge that this reach to about +1 with increase of the diameter of Cation and fullerene and with moving the Cation toward the center of hollow sphere.

It is obvious and worthwhile that in all $\mathrm{FH}^{+}$systems and $\mathrm{FLi}^{+}$ systems with small diameters, the charge transferred between Cation and fullerene and fullerene achieved the positive charge. This finding can be useful in the fuel hydrogen cells, Li batteries, nano electrode science and the processes of remove of charged pollutants.
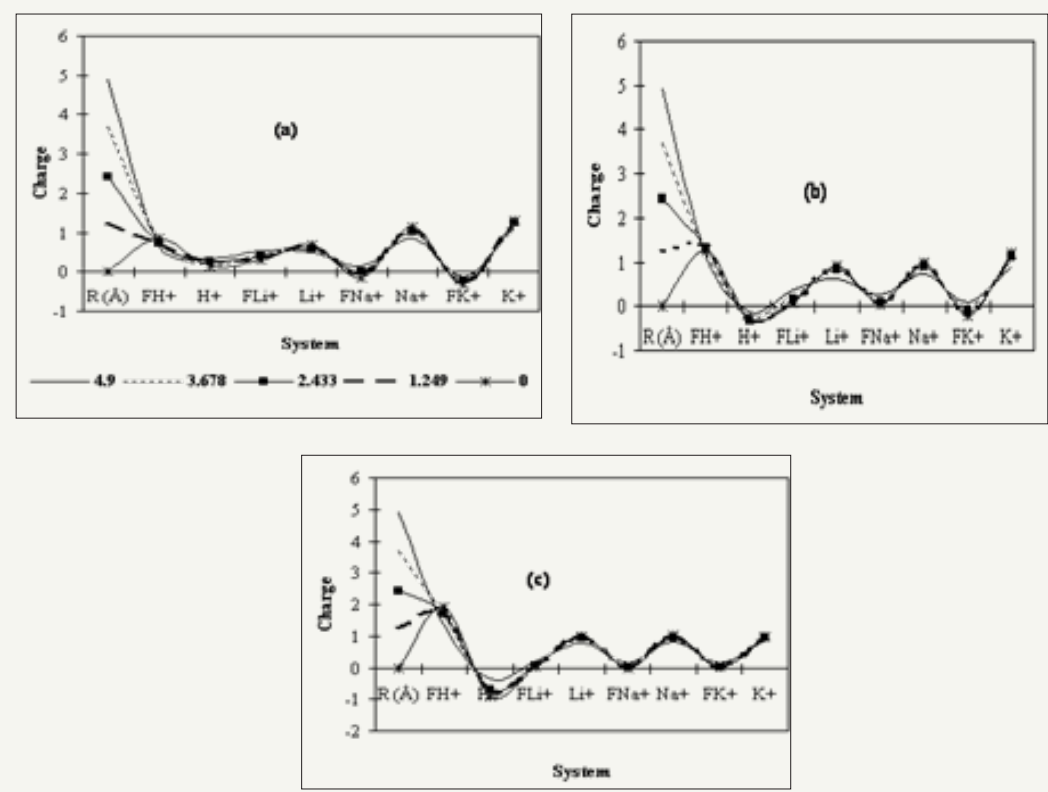

Figure 3: The charge of Cations of $\mathrm{H}^{+}, \mathrm{Li}+, \mathrm{Na}^{+}$and $\mathrm{K}+$ single and systems in trapped of Fullerene at different distance (4.9, $3.678,2.433,1.249$ and in the center of cage) as (a)C60 (b)C70 (c)C80 fullerenes. 
In the all fullerenes $\left(\mathrm{C}_{60}, \mathrm{C}_{70}\right.$ and $\mathrm{C}_{80}$, the charges of carbon atoms are negative. However, by entry of Cations, we have observed reduction of the charge of carbon atoms around of Cation (Figure 3). This fact has shown that Cations have maintained positive charges while transferring electron density to a localized region on the fullerenes. But in the $\mathrm{C}_{70}$ and $\mathrm{C}_{80}$ fullerene $\mathrm{H}^{+}$system, the charge of carbon atoms become more positive (Figure 3).

Figure 3 has evidenced the charge of Cations and total charge of hollow sphere $\left(\mathrm{C}_{60}, \mathrm{C}_{70}\right.$ and $\left.\mathrm{C}_{80}\right)$-Cation systems at situations of Cations along central axis of cages. Endohedral fullerenes are fullerenes that have additional atoms, ions, or clusters enclosed within their inner spheres [37]. Doping fullerenes with electropositive metals takes place in an arc reactor or via laser evaporation. The metals can be transition metals like scandium, yttrium as well as lanthanides like lanthanum and cerium. Also possible are endohedral complexes with elements of the alkaline earth metals like barium and strontium, alkali metals like potassium and tetravalent metals like uranium, zirconium and hafnium.

Endohedral metallofullerenes are characterized by the fact that electrons will transfer from the metal atom to the fullerene cage and that the metal atom takes a position off-center in the cage [37]. The size of the charge transfer is not always simple to determine. In most cases it is between 2 and 3 charge units, in the case of the $\mathrm{C}_{60}, \mathrm{C}_{70}$ and $\mathrm{C}_{80}$ fullerenes however it can be electrons such as in compounds which is better described as complex [38]. In this investigation, the Cationic fullerene cages have been very stable molecules and do not have the reactivity associated with ordinary empty fullerenes (Figure 3).

\section{Conclusion}

In this investigation, all computations on diffusion pathway for $\mathrm{H}^{+}, \mathrm{Li}^{+}, \mathrm{Na}^{+}, \mathrm{K}^{+}$Cations to move through the $\mathrm{C}_{60}, \mathrm{C}_{70}$ and $\mathrm{C}_{80}$ fullerenes with density functional theory (DFT) technique have carried out via Gaussian03 package at the level of density functional theory (DFT) using the hybrid exchange-functional B3LYP method at $6-31+G^{* *}$, $6-31++G^{* *}$ standard basis sets that were sufficient for structural optimization of fullerenes, in summary we have concluded:

1. In the $\mathrm{C}_{60}, \mathrm{C}_{70}$ and $\mathrm{C}_{80}$ fullerenes, the Cations had nonbonded interactions with these compounds.

2. Structures of the $\mathrm{C}_{60}, \mathrm{C}_{70}$ and $\mathrm{C}_{80}$ fullerenes with various metallic cations are allowed to fully relax during the several optimization processes.

3. Electrical resistance Properties of the structures have calculated using prior calculation by measurement of charge transfer between of the $\mathrm{C}_{60}, \mathrm{C}_{70}$ and $\mathrm{C}_{80}$ fullerenes and $\mathrm{H}^{+}, \mathrm{Li}^{+}, \mathrm{Na}^{+}$, $\mathrm{K}^{+}$Cations.

4. In NMR scrutiny used prior method with $6-31+\mathrm{G}^{* *}$ $6-31++G^{* *}$ basis sets, good agreement together in results.

These compounds can be miniaturized electronics beyond the micro electromechanical scale currently used in electronics.

\section{References}

1. Iijima S (1980) Direct observation of the tetrahedral bonding in graphitized carbon black by high resolution electron microscopy. Journal of Crystal Growth 50: 675-683.

2. Buseck PR, Tsipursky SJ, Hettich R (1992) Fullerenes from the geological environment. Science 257(5067): 215-217.

3. Cami J, Salas B, Peeters J, Malek E (2010) Detection of C60 and C70 in a young planetary nebula. Science 329(5996): 1180-1182.

4. Beavers CM (2006) $\mathrm{Tb}_{3} \mathrm{~N} @ \mathrm{C}_{84}$ : An improbable, egg-shaped endohedral fullerene that violates the isolated pentagon rule. Journal of the American Chemical Society 128: 11352-11353.

5. Luann B (2007) Impact event at the permian-triassic boundary: evidence from extraterrestrial noble gases in fullerenes. Science 291(5508): 1530-1533.

6. Mraz SJ (2005) A new buckyball bounces into town. Machine Design, USA.

7. Locke W (1996) Buckminsterfullerene: Molecule of the Month, Bristol University, UK.

8. Meija J (2006) Goldberg variations challenge. Analytical and Bioanalytical Chemistry 385(1): 6-7.

9. Monajjemi M, Baei MT, Mollaamin F (2008) Russian Journal of Inorganic Chemistry 53: 1430-1437.

10. Karger J, Ruthven DM (1992) Diffusion in zeolites and other microporous solids. In: Karger J, Ruthven DM (Eds.), Developments in Chemical engineering and Mineral Processing Banner, John Wiley, New York, USA.

11. Mollaamin F (2017) Quantum studies of dopamine delivery to brain by boron nitride nanotube through learning a new language. J Comput Theor Nanosci 14(5): 2429-2434

12. Monajjemi M, Lee VS, Khaleghian M, Honarparvar B, Mollaamin F (2010) Theoretical description of electromagnetic nonbonded interactions of radical, cationic, and anionic $\mathrm{NH}_{2} \mathrm{BHNBHNH}_{2}$ Inside of the $\mathrm{B}_{18} \mathrm{~N}_{18}$ nanoring. J Phys Chem C 114: 15315.

13. Fatemeh M (2017) Bioorganic adsorption on nano-clusters through disabling language cognition. Adv Nano Bio M\&D 1(3): 135-145.

14. Levitt DG (1973) Dynamics of a single-file pore: non-fickian behavior Phys Rev A 8: 3050.

15. Gokel GW, Murillo O (1996) Synthetic organic chemical models for transmembrane channels. Acc Chem Res 29(9): 425-432.

16. Iijima S (1991) Helical microtubules of graphitic carbon. Nature 354: 56-58.

17. Monajjemi M, Mahdavian L, Mollaamin F (2008) Characterization of nanocrystalline silicon germanium film and nanotube in adsorption gas by Monte Carlo and Langevin dynamic simulation. Bull Chem Soc Ethiop 22(2): 277-286

18. Mintmire JW, Dunlap BI, White CT (1992) Are fullerene tubules metallic? Physical Review Letters 68: 631.

19. Dekker C (1999) Carbon nanotubes as molecular quantum wires. Physics Today 52: 22.

20. Martel R, Derycke V, Lavoie C, Appenzeller J, Chan KK, et al. (2001) Ambipolar electrical transport in semiconducting single-wall carbon nanotubes. Physical Review Letters 87: 256805.

21. Meunier V, Kephart J, Roland C, Bernholc J (2002) First-order transition in the spin dynamics of geometrically frustrated $\mathrm{Yb}_{2} \mathrm{Ti}_{2} \mathrm{O}_{7}$. Phys Rev Let 88: 7.

22. Monajjemi M, Mahdavian L, Molaamin F, Khaleghian M (2009) Interaction of $\mathrm{Na}, \mathrm{Mg}, \mathrm{Al}, \mathrm{Si}$ with carbon nanotube (CNT): NMR and IR study. Russian Journal of Inorganic Chemistry 54(9): 1465-1473. 
23. Fatemeh M (2017) Language acquisition and perception through the role of nano chemical neurotransmitters in the brain. Adv Nano Bio M\&D 1(1): 48-53.

24. Mollaamin F, Baei MT, Monajjemi M, Zhiani R, Honarparvar B (2008) Russian Journal of Physical Chemistry A 82: 2354.

25. Hummer G, Rasaiah JC, Noworyta JP (2001) Water conduction through the hydrophobic channel of a carbon nanotube. Nature 414: 188-190.

26. Mann DJ, Halls MD (2003) Water alignment and proton conduction inside carbon nanotubes. Phys Rev Lett 90: 195503.

27. Berezhkovskii A, Hummer G (2002) Absence of static phase separation in the high Tc cuprate $\mathrm{YBa}_{2} \mathrm{Cu}_{3} \mathrm{O}_{6+\mathrm{y}}$. Phys Rev Lett 89: 6 .

28. Monajjemi M, Chegini H, Mollaamin F, Farahani P (2011) Theoretical studies of solvent effect on normal mode analysis and thermodynamic properties of zigzag $(5,0)$ carbon nanotube. Fullerenes, Nanotubes and Carbon Nanostructures 19(5): 469-482.

29. Guha S, Nakamoto K (2005) Electronic structures and spectral properties of endohedral fullerenes. Coord Chem Rev 249(9-10): 1111-1132.

30. Cioslowski J, Fleischmann ED (1991) Endohedral complexes: Atoms and ions inside the $\mathrm{C}_{60}$ cage. J Chem Phys 94: 3730.
31. Frisch MJ (2004) Gaussian 03, RevisionC 02, Gaussian, Inc, Wallingford CT, UK.

32. Becke AD (1993) A new mixing of Hartree-Fock and local densityfunctional theories. J Chem Phys 98: 5648.

33. Dresselhaus MS, Dresselhaus G, Eklund PC (1996) Science of fullerenes and carbon nanotubes academic, San Diego, USA.

34. Pavanello M, Jalbout AF, Trzaskowski B, Adamowicz L (2007) Fullerene as an electron buffer: Charge transfer in Li@C $0_{60}$. Chem Phys Lett 442(46): $339-343$

35. Zhao J, Buldum A, Han J, Lu JP (2000) First-Principles study of liintercalated carbon nanotube ropes. Phys Rev Lett 85: 1706.

36. Udomvech A, Kerdcharoen T, Osotchan T (2005) First principles study of $\mathrm{Li}$ and $\mathrm{Li}^{+}$adsorbed on carbon nanotube: Variation of tubule diameter and length. Chemical Physics Letters 406(1-3): 161-168.

37. Ge Z, Duchamp J, Cai TG, Dorn H (2005) Purification of endohedral trimetallic nitride fullerenes in a single, facile step. Journal of the American Chemical Society 127(46): 16292-16298.

38. Muthukumar K, Larsson JA (2008) Functional nanofibers for environmental applications. Journal of Materials Chemistry 18: 3347.

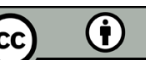

Creative Commons Attribution 4.0

International License

For possible submissions Click Here
Submit Article

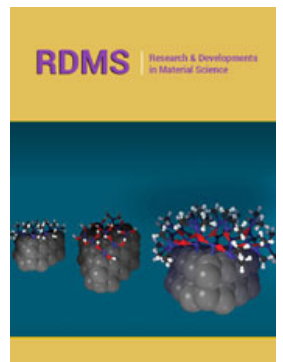

\section{Research \& Development in Material Science}

\section{Benefits of Publishing with us}

- High-level peer review and editorial services

- Freely accessible online immediately upon publication

- Authors retain the copyright to their work

- Licensing it under a Creative Commons license

- Visibility through different online platforms 